\title{
PENGARUH KOMPETENSI MANAJERIAL KEPALA SEKOLAH DAN BUDAYA ORGANISASI SEKOLAH TERHADAP MOTIVASI KERJA GURU DI SEKOLAH ISLAM AL-HAMÎD JAKARTA TIMUR
}

\author{
THE IMPACT OF MANAGERIAL COMPENTENCIES OF THE SCHOOL \\ PRINCIPAL AND THE ORGANIZATIONAL CULTURE ON TEACHERS' WORK \\ MOTIVATION AT SEKOLAH ISLAM AL-HAMÎD, EAST JAKARTA
}

\author{
Ainur Alam Budi Utomo \\ Program Studi Manajemen \\ Fakultas Ekonomi dan Bisnis \\ Universitas Buana Perjuangan Karawang \\ Email : ainuralambudiutomo@ubpkarawang.ac.id
}

\begin{abstract}
ABSTRAK
Penelitian ini bertujuan untuk mengetahui dan menguji data-data empirik terkait pengaruh kompetensi manajerial kepala sekolah dan budaya organisasi sekolah terhadap motivasi kerja guru secara simultan. Dalam penelitian ini, penulis menggunakan metode survei dengan pendekatan korelasional dan regresional terhadap data-data kuantitatif yang diperoleh dari objek penelitian yaitu guru-guru Sekolah Islam Al-Hamîd Jakarta Timur. Sampel penelitian ini sebanyak 80 responden dari total 100 guru di Sekolah Islam Al-Hamîd Jakarta Timur. Pengumpulan data dilakukan dengan menggunakan teknik angket/kuesioner, observasi, dan dokumentasi. Jenis analisis yang digunakan adalah analisa korelasi dan regresi yang dijabarkan secara deskriptif. Hasil dari penelitian ini adalah terdapat pengaruh yang positif dan signifikan Kompetensi Manajerial Kepala Sekolah dan Budaya Organisasi Sekolah Secara simultan terhadap Motivasi Kerja Guru di Sekolah Islam Al-Hamîd Jakarta Timur dengan koefisien korelasi ( $\mathrm{r}$ ) sebesar 0,500 dan koefisien determinasi $\left(\mathrm{R}^{\mathrm{s}}\right)$ sebesar $25 \%$. Arah pengaruh ditunjukan dengan persamaan regresi $\hat{Y}=44,471+0,324 \mathrm{X}_{1}+0,370 \mathrm{X}_{2 .}$. Dari persamaan ini dapat dibaca bahwa setiap kenaikan 1 poin kompetensi manajerial kepala sekolah $\left(\mathrm{X}_{1}\right)$ dan Budaya Organisasi Sekolah $\left(\mathrm{X}_{2}\right)$ Secara bersama-sama akan diikuti kenaikan motivasi kerja guru $(\mathrm{Y})$ sebesar 0,694 poin.
\end{abstract}

Kata Kunci: Kompetensi Manajerial, Budaya Organisasi Sekolah, Motivasi Kerja Guru.

\begin{abstract}
This research aims to identify and test empirical data about the impact of managerial competencies of the school principal and the organizational culture on teachers' work motivation simultaneously. In this research, I used survey method with correlational and regressional approach on quantitative data obtained from the teachers of Sekolah Islam Al-Hamîd, East Jakarta. The samples of this research are 80 respondents from the population of 100 teachers at Sekolah Islam Al-Hamîd, East Jakarta. Datas were gathered through questionnaires distribution, observation, and documentation. The datas then were analiyzed using correlation regression analysis which are elaborated descriptively. The results of this research are there is positive and significant impact of organizational atsmosphere on teacher's work motivation and organizational atsmosphere on teacher's work motivation at Sekolah Islam Al-Hamîd, East Jakarta simultaneously with coefficient of correlation (r) of 0,500 and coefficient of determination $\left(R^{s}\right)$ of $25 \%$. The regression equation is $\hat{Y}=44,471+$ $0,324 X_{1}+0,370 X_{2}$. This means that every 1 point increase of the school principal's managerial competences $\left(\mathrm{X}_{1}\right)$ and the organizational atsmosphere $\left(\mathrm{X}_{2}\right)$ is simultaneously followed by the increase of teacher's work motivation (Y) of 0,694 point.
\end{abstract}

Key words: managerial competencies, school organizational culture, teacher's work motivation. 


\section{PENDAHULUAN}

Berbicara tentang pelaksana pendidikan di sekolah, khususnya kepala sekolah dan guru sangatlah menarik untuk diteliti. Terlebih keduanya memiliki peran yang sangat signifikan dalam membangun kemajuan sekolah dan karakter peserta didik. Tentunya untuk menghasilkan peserta didik yang berkarakter, diperlukan perhatian khusus, terutama menyangkut budaya organisasi sekolah itu sendiri. Ketika budaya organisasi sekolah itu baik berkat peran kepala sekolah dan guru, maka sekolah tersebut dikatakan "sekolah sehat" atau dengan istilah lain disebut dengan "sekolah efektif". Namun sebaliknya, apabila budaya organisasi sekolah itu buruk karena peran kepala sekolah dan guru, maka sekolah tersebut dinamakan dengan nama "sekolah tidak sehat" atau juga disebut dengan "sekolah tidak efektif'.

Di sisi lain juga jika mengkaji perkembangan pendidikan secara teoritis dan praktis tentang kompetensi seorang kepala sekolah, sudah selayaknya kompetensi seorang kepala sekolah harus terus-menerus dioptimalkan dan dikembangkan kemampuannya. Tidak hanya mencukupkan diri dengan berlabel kepala sekolah, akan tetapi kosong dari makna dan fungsinya sebagai kepala sekolah. Kepala sekolah yang berkompeten secara teoritis dan praktis memiliki nilai plus, yaitu mampu mewujudkan budaya organisasi sekolah yang sehat bagi guru, siswa dan pegawainya, sehingga proses pelaksanaan kegiatan pendidikan di sekolah pun berjalan sesuai dengan visi dan misi sekolah yang akan dicapai. Bahkan menurut Novianti Djafri untuk menilai kualitas kinerja sekolah dapat dilihat salah satunya dari kepemimpinan kepala sekolah. Lebih detailnya menurut Novianti Djafri (2016:4) mengatakan "Untuk menilai kinerja sekolah dapat dilihat dari tiga hal, yaitu : (1) Profil sekolah sebagai input, (2) kepemimpinan kepala sekolah sebagai proses dan (3) prestasi sekolah sebagi hasil”.

Kepala sekolah sebagai pemimpin pendidikan di sekolah, lebih tepatnya harus menjadi dinamisator dan komando dalam menggerakkan segenap potensi tenaga pendidik dan kependidikan, khususnya guru dalam rangka mencapai tujuan dengan cara membantu para guru secara kooperatif untuk meningkatkan kinerja, karena mereka menginginkan kepala sekolah yang bukan saja secara teoritis memiliki syarat-syarat kepemimpinan umumnya, tetapi yang terpenting adalah penerapan melalui kepemimpinan yang benar-benar dirasakan dan berpengaruh terhadap kinerja guru. 
Ainur Alam Budi Utomo

Vol 4 No 2

ISSN : 2541-6995

E ISSN : 2580-5517

Sebagai contoh, secara teoritis dan praktis seorang kepala sekolah dengan membawa visi dan misi yang di emban dan sebagai pemimpin dalam organisasi, seharusnya memiliki berbagai kompetensi yang harus dikembangkan dan diaplikasikan dalam sekolah. Menurut E.Mulyasa (2013:98) "Kompetensi yang harus dimiliki oleh kepala sekolah yaitu ; kompetensi edukator, manajer, administrator, supervisor, leader, innovator dan motivator".

Selain kompetensi kepala sekolah yang telah disebutkan juga, di antara hal terpenting bagi seorang kepala sekolah yang harus dilakukan adalah membangun budaya organisasi sekolah. Budaya organisai sekolah yang dimaksud adalah menjadikan identitas sekolah menjadi family culture, machine culture, cabaret culture atau little shop of horrors culture (Uhar Suharsaputra, 2013:120). Sebagai contoh kecil dalam konteks budaya organisasi sekolah, kepala sekolah bersama guru menerapkan pendidikan karakter bagi peserta didik secara berkepanjangan. Terlebih lagi, program pendididkan karakter (PPK) saat ini merupakan program revolusi mental yang dilakukan oleh pemerintah. Dalam harian Radar Karawang (2016, Januari 4) menurut Menteri Pendidikan dan Kebudayaan (Mendikbud) Muhadjir Effendy, di akhir tahun 2016 PPK telah diimplementasikan di 542 sekolah di 34 provinsi. Kemudian menurutnya juga, penguatan 5 nilai utama karakter akan diterapkan di sekolah sebagai contoh PPK. Target tersebut akan sampai dengan 2020. Adapun penguatan nilai tersebut yaitu : "relegius, nasionalis, mandiri, gotong royong dan integritas pada 3 kegiatan inti (intrakurikuler, kokurikuler, ekstrakurikuler)".

Kondisi pendidikan di Indonesia, khususnya mengenai kualitas pendidikan di sekolah belumlah mengalami kemajuan. Hal tersebut berdasarkan perkataan Qian Tang, asisten Direktur Jenderal untuk Pendidikan dari The United Nations Educational, Scientific and Cultural Organization (UNESCO) mengatakan bahwa mutu pendidikan belum menjadi prioritas pemerintah Indonesia. Padahal, angka partisipasi siswa bersekolah tanpa diiringi dengan penyediaan kualitas pendidikan yang baik, tidak akan berdampak banyak pada kualitas individu tersebut. Oleh karenanya menurut Tang, kendala yang dihadapi Pemerintah Indonesia adalah memastikan seluruh anak bersekolah mendapatkan kualitas pendidikan yang sama (diakses dari : https://www.cnnindonesia.com/nasional/20160906155806-20156462/unesco-soroti-kesenjangan-kualitas-pendidikan-di-indonesia).

Atas dasar pernyatan Qian Tang tersebut di atas, dapat di analisis bahwa perlunya diadakan penelitian lebih mendalam pada kendala kualitas lembaga pendidikan di Indonesia, terutama di lembaga pendidikan Islam. Asumsi tersebut bisa disebabkan oleh pengaruh kompetensi manajerial kepala sekolah dan budaya organisasi sekolah terhadap motivasi 
Ainur Alam Budi Utomo

Vol 4 No 2

ISSN : 2541-6995

E ISSN : 2580-5517

kerja guru itu sendiri seperti pada penelitian berikut ini yang dilakukan di Sekolah Islam AlHamîd Jakarta Timur.

\section{METODE PENELITIAN}

Penelitian ini adalah kuantitatif. Menurut Sugiyono (2006:8) "Penelitian kuantitatif dapat diartikan sebagai metode untuk meneliti pada populasi atau sampel tertentu, pengumpulan data menggunakan instrument penelitian, analisis data bersifat kuantitatif/statistik, dengan tujuan untuk menguji hipotesis yang telah ditetapkan”.

Dalam penelitian ini menggunakan metode survei dengan pendekatan korelasional. Metode survei sendiri adalah mengumpulkan data atau informasi tentang populasi yang besar dengan menggunakan sampel yang relative kecil. Populasi tersebut bisa berkenaan dengan orang, instansi, lembaga, organisasi, unit kemasyarakatan, dan lain-lain tetapi sumber utamanaya adalah orang (Nana Syaodih Sukmadinata, 2012:82).

Dalam metode survei, data dikumpulkan dari sampel atas populasi dan menggunakan kuesioner sebagai alat pengumpulan data yang pokok. Selain itu juga, dengan metode survei dapat membedah, membahas, dan mengenal masalah-masalah, serta mendapatkan pembenaran terhadap keadaan praktik-praktik yang sedang berlangsung. Kemudian juga, dengan metode survei dapat dilakukan evaluasi serta perbandingan-perbandingan terhadap hal-hal yang dikerjakan orang dalam menangani situasi atau masalah yang serupa dan hasilnya dapat digunakan dalam pembuatan rencana dan pengambilan keputusan di masa mendatang. Sedangkan pendekatan koresional yang dimaksud adalah pendekatan dalam penelitian yang pada pelaksanaannya menggunakan tehnik analisis yang dinamakan korelasi. Menurut Anas Sudijono (2000:175) “Tehnik analisa korelasional adalah tehnik analisa statistik mengenai hubungan antara dua variabel atau lebih".

Penelitian ini dilaksanakan di Yayasan Mantab Al-Hamîd Jakarta Timur sebagai badan hukum dari Sekolah Islam Al-Hamîd Jakarta Timur yang memiliki dan mengelola dari tingkat Taman Kanak-Kanak Islam, Madrsah Ibtidaiyyah, Madrasah Tsanawiyah dan Madrasah Aliyah. Adapun waktu penelitian, dilakukan pada bulan September sampai dengan Oktober di Yayasan Mantab Al-Hamîd yang beralamat di Jl. Cilangkap Baru, No. 1 Cilangkap, Cipayung Jakarta Timur 1780.

Subjek dalam penelitian ini adalah populasi dari keseluruhan guru di Yayasan Mantab Al-Hamîd Jakarta Timur, sedangkan sampel mengambil dari $25 \%$ dari keseluruhan guru dengan tingkat presisi 0,05 \% dengan menggunakan rumus Slovin dalam Ridwan (2002:47) 
sebagaimana perhitungan berikut di bawah ini :

$$
n=\frac{N}{1+N d^{2}}
$$

$$
\begin{aligned}
& \text { Keterangan : } \\
& \mathrm{n}=\text { Jumlah sampel } \\
& \mathrm{N}=\text { Jumlah populasi } \\
& \mathrm{d} 2=\text { Presisi yang ditetapkan }(0,05)
\end{aligned}
$$

Jumlah populasi dalam penelitian adalah sebanyak 100 orang, maka pengambilan sampelnya adalah 80 orang dengan perhitungan sebagai berikut :

$$
\begin{gathered}
n=\frac{100}{1+100 \cdot(0,05) 2} \\
n=\frac{100}{1+100(0,0025)} \\
n=\frac{100}{1+0,25} \\
n=\frac{100}{1,25} \\
n=80
\end{gathered}
$$

Penarikan sampel pada penelitian ini juga dilakukan dengan cara acak atau random sampling. Teknik random sampling ini merupakan teknik pengambilan sampel dengan cara mencampur adukan subyek-subyeknya di dalam populasi sehingga semua obyek dianggap sama. Adapaun teknik pengumpulan data dalam penelitian yaitu dengan teknik angket/kuesioner, observasi, dan dokumentasi yang digunakan untuk mendapatkan data mengenai kompetensi manajerial kepala sekolah, budaya organisasi sekolah dan motivasi kerja guru.

\section{HASIL PENELITIAN}


Ainur Alam Budi Utomo

Vol 4 No 2

ISSN : 2541-6995

E ISSN : 2580-5517

Secara berturut-turut berikut akan dijelaskan gambaran deskriptif ketiga variabel yang diteliti, yaitu Motivasi Kerja Guru (Y); Kompetensi Manajerial Kepala Sekolah ( $\mathrm{X}_{1}$ ); dan Budaya Organisasi Sekolah $\left(\mathrm{X}_{2}\right)$.

Ketiga jenis data diperoleh melalui dua teknik pengumpulan data berupa kuesioner atau angket yang sebelumnya telah dirancang oleh peneliti sesuai dengan indikator setiap variabel yang diteliti.

\section{a. Motivasi Kerja Guru (Variabel Y)}

Setelah melalui proses editing dan skoring, data kemudian ditabulasi untuk menemukan total skor dari jawaban tiap responden. Tabel tabulasi data dapat dilihat pada bagian di lampiran. Data total skor angket tersebut dideskripsikan pada tabel berikut :

Tabel

Data Deskriptif Variabel Motivasi Kerja Guru (Y)

\begin{tabular}{|c|l|c|}
\hline No. & \multicolumn{1}{|c|}{ Aspek Data } & Skor \\
\hline \hline 1 & N (total responden) & 80 \\
\hline 2 & Mean (rata-rata) & 157.25 \\
\hline 3 & Std. Error of Mean (rata-rata kesalahan standar) & 0.890 \\
\hline 4 & Median (skor tengah) & 158 \\
\hline 5 & Mode (skor yang sering muncul) & 157 \\
\hline 6 & Std. Deviation (simpang baku) & 7.958 \\
\hline 7 & Variance (varian) & 63.329 \\
\hline 8 & Range (rentang skor) & 36 \\
\hline 9 & Minimum (skor tertinggi) & 135 \\
\hline 10 & Maximum (skor terendah) & 171 \\
\hline 11 & Sum (total skor) & 12580 \\
\hline
\end{tabular}

Berdasarkan tabel di atas, maka data deskriptif variabel motivasi kerja guru (Y) yang di peroleh dari hasil penelitian, menunjukkan bahwa dengan jumlah responden (N) 80 orang, skor rata-rata 157,25 atau sama dengan $85 \%$ dari skor idealnya yaitu 187. Data ini dapat ditafsirkan sebagai tingkat atau taraf perkembangan variabel motivasi kerja guru dengan kriteria sebagai berikut :

$$
\begin{array}{ll}
90 \%-100 \% & =\text { Sangat tinggi } \\
80 \%-89 \% & =\text { Tinggi } \\
70 \%-79 \% & =\text { Cukup tinggi } \\
60 \%-69 \% & =\text { Sedang } \\
50 \%-59 \% & =\text { Rendah }
\end{array}
$$


$40 \%$ ke bawah $=$ Sangat rendah

Merujuk pada kriteria tersebut di atas, maka dapat ditafsirkan bahwa motivasi kerja guru pada saat ini berada pada taraf $85 \%$. Hal ini menunjukkan bahwa motivasi kerja guru pada taraf yang tinggi.

Adapun tabel distribusi frekuensi dan gambar histogram dari variabel motivasi kerja guru (Y) ini adalah sebagai berikut :

\section{Tabel}

Distribusi Frekuensi

Skor Variabel Motivasi kerja Guru (Y)

\begin{tabular}{|c|c|c|c|}
\hline & \multirow{2}{*}{ Kelas Interval } & Frekuensi (Fi) & \multicolumn{2}{|c|}{ Frekuensi } \\
\cline { 3 - 5 } & & Relatif & Komulatif (\%) \\
\hline $135-139$ & 4 & $5.00 \%$ & $5.00 \%$ \\
\hline $140-144$ & 5 & $6.25 \%$ & $11.25 \%$ \\
\hline $145-149$ & 1 & $1.25 \%$ & $12.50 \%$ \\
\hline $150-154$ & 7 & $8.75 \%$ & $21.25 \%$ \\
\hline $155-159$ & 31 & $38.75 \%$ & $60.00 \%$ \\
\hline $160-164$ & 21 & $26.25 \%$ & $86.25 \%$ \\
\hline $165-169$ & 8 & $10.00 \%$ & $96.25 \%$ \\
\hline $170-174$ & 3 & $3.75 \%$ & $100.00 \%$ \\
\hline Jumlah & 80 & $100 \%$ & \\
\hline
\end{tabular}

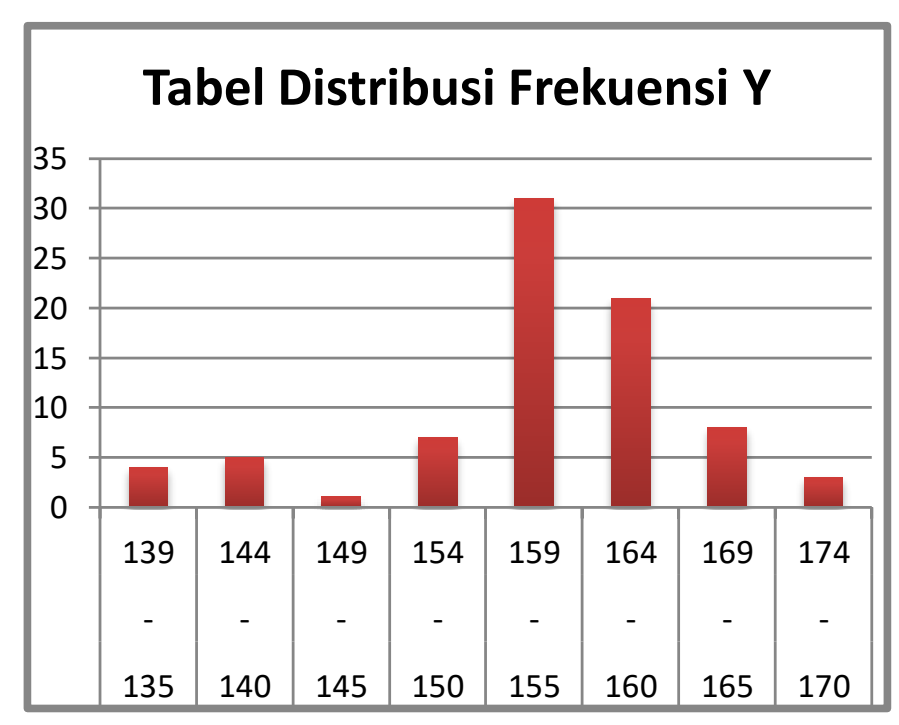

Gambar

Histogram Variabel Motivasi Kerja Guru (Y) 


\section{b. Kompetensi Manajerial Kepala Sekolah (Variabel $\mathbf{X}_{1}$ )}

E ISSN : 2580-5517

Setelah melalui proses editing dan skoring, data kemudian ditabulasi untuk menemukan total skor dari jawaban tiap responden. Tabel tabulasi data dapat dilihat pada bagian di lampiran. Data total skor angket tersebut dideskripsikan pada tabel berikut :

Tabel

Data Deskriptif Variabel Manajerial Kepala Sekolah $\left(\mathbf{X}_{1}\right)$

\begin{tabular}{|c|l|c|}
\hline No. & \multicolumn{1}{|c|}{ Aspek Data } & Skor \\
\hline \hline 1 & N (total responden) & 80 \\
\hline 2 & Mean (rata-rata) & 162.313 \\
\hline 3 & Std. Error of Mean (rata-rata kesalahan standar) & 0.867 \\
\hline 4 & Median (skor tengah) & 163 \\
\hline 5 & Mode (skor yang sering muncul) & 167 \\
\hline 6 & Std. Deviation (simpang baku) & 7.755 \\
\hline 7 & Variance (varian) & 60.142 \\
\hline 8 & Range (rentang skor) & 36 \\
\hline 9 & Minimum (skor tertinggi) & 144 \\
\hline 10 & Maximum (skor terendah) & 180 \\
\hline 11 & Sum (total skor) & 12985 \\
\hline
\end{tabular}

Berdasarkan tabel di atas, maka data deskriptif variabel Kompetensi Manajerial Kepala Sekolah $\left(\mathrm{X}_{1}\right)$ yang di peroleh dari hasil penelitian, menunjukkan bahwa dengan jumlah responden (N) 80 orang, skor rata-rata 162,31.

Memperhatikan skor rata-rata variabel Kompetensi Manajerial Kepala Sekolah yaitu 162,31 atau sama dengan $87,7 \%$ dari skor idealnya yaitu 185 . Data ini dapat ditafsirkan sebagai tingkat atau taraf perkembangan variabel tersebut berada pada taraf tinggi $(87,7 \%)$. Hal ini menunjukkan bahwa Kompetensi Manajerial Kepala Sekolah sangat baik.

Adapun tabel distribusi frekuensi dan gambar histogram dari variabel $\mathrm{X}_{1}$ ini adalah sebagai berikut :

\section{Tabel}

Distribusi Frekuensi

Skor Variabel Kompetensi Manajerial Kepala Sekolah $\left(\mathrm{X}_{1}\right)$

\begin{tabular}{|l|l|l|}
\hline Kelas Interval & Frekuensi (Fi) & Frekuensi \\
\hline
\end{tabular}


E ISSN : 2580-5517

\begin{tabular}{|cc|c|c|c|}
\hline & & & Relatif & Komulatif (\%) \\
\hline $144-148$ & 4 & $5.00 \%$ & $5.00 \%$ \\
\hline $149-153$ & 4 & $5.00 \%$ & $10.00 \%$ \\
\hline $154-158$ & 16 & $20.00 \%$ & $30.00 \%$ \\
\hline $159-163$ & 19 & $23.75 \%$ & $53.75 \%$ \\
\hline $164-168$ & 21 & $26.25 \%$ & $80.00 \%$ \\
\hline $169-173$ & 9 & $11.25 \%$ & $91.25 \%$ \\
\hline $174-178$ & 6 & $7.50 \%$ & $98.75 \%$ \\
\hline $179-183$ & 1 & $1.25 \%$ & $100.00 \%$ \\
\hline Jumlah & 80 & $100 \%$ & \\
\hline
\end{tabular}

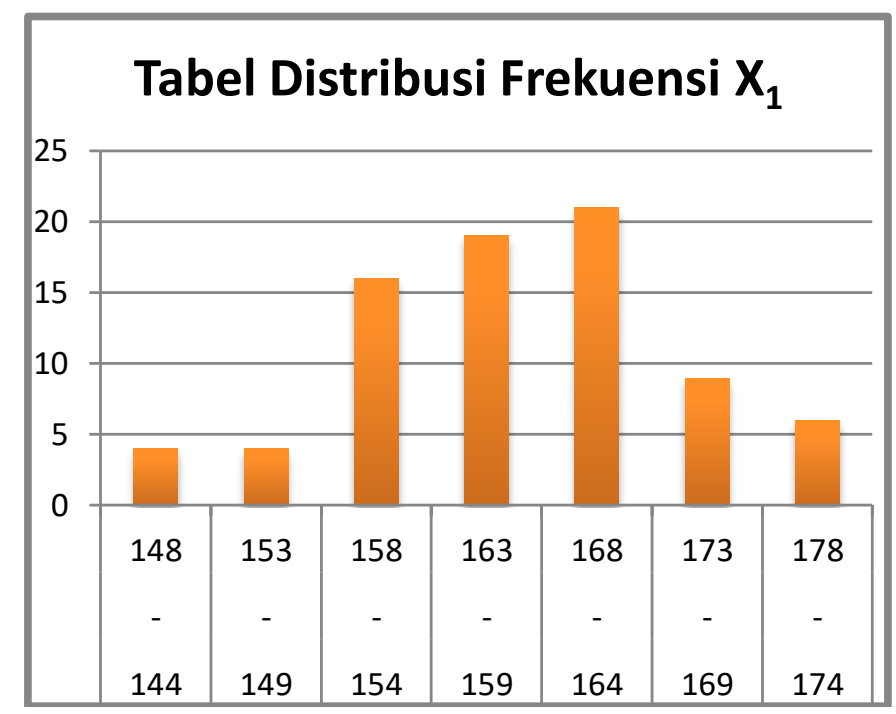

Gambar Histogram

Variabel Kompetensi Manajerial Kepala Sekolah $\left(\mathbf{X}_{1}\right)$

\section{c. Budaya Organisasi Sekolah (Variabel $\mathbf{X}_{2}$ )}

Setelah melalui proses editing dan skoring, data kemudian ditabulasi untuk menemukan total skor dari jawaban tiap responden. Tabel tabulasi data dapat dilihat pada bagian di lampiran. Data total skor angket tersebut dideskripsikan pada tabel berikut :

Tabel

Data Deskriptif Variabel Budaya Organisasi Sekolah $\left(\mathbf{X}_{2}\right)$

\begin{tabular}{|c|l|c|}
\hline No. & \multicolumn{1}{|c|}{ Aspek Data } & Skor \\
\hline \hline 1 & N (total responden) & 80 \\
\hline 2 & Mean (rata-rata) & 162.563 \\
\hline 3 & Std. Error of Mean (rata-rata kesalahan standar) & 0.756 \\
\hline
\end{tabular}




\begin{tabular}{|c|l|c|}
4 & Median (skor tengah) & 164 \\
\hline 5 & Mode (skor yang sering muncul) & 163 \\
\hline 6 & Std. Deviation (simpang baku) & 6.760 \\
\hline 7 & Variance (varian) & 45.692 \\
\hline 8 & Range (rentang skor) & 31 \\
\hline 9 & Minimum (skor tertinggi) & 142 \\
\hline 10 & Maximum (skor terendah) & 173 \\
\hline 11 & Sum (total skor) & 13005 \\
\hline
\end{tabular}

Berdasarkan tabel di atas, maka data deskriptif variabel Budaya Organisasi Sekolah $\left(\mathrm{X}_{2}\right)$ yang di peroleh dari hasil penelitian, menunjukkan bahwa dengan jumlah responden $(\mathrm{N}) 80$ orang, skor rata-rata 162,56.

Memperhatikan skor rata-rata variabel Kompetensi Manajerial Kepala Sekolah yaitu 162,56 atau sama dengan $87,9 \%$ dari skor idealnya yaitu 185 . Data ini dapat ditafsirkan sebagai tingkat atau taraf perkembangan variabel tersebut berada pada taraf tinggi $(87,9 \%)$. Hal ini menunjukkan bahwa Budaya Organisasi Sekolah sangat baik.

Adapun tabel distribusi frekuensi dan gambar histogram dari variabel $\mathrm{X}_{2}$ ini adalah sebagai berikut :

Tabel

Distribusi Frekuensi

Skor Variabel Budaya Organisasi Sekolah $\left(\mathbf{X}_{2}\right)$

\begin{tabular}{|c|c|c|c|c|}
\hline \multirow{2}{*}{\multicolumn{2}{|c|}{ Kelas Interval }} & \multirow{3}{*}{$\begin{array}{c}\text { Frekuensi (Fi) } \\
3\end{array}$} & \multicolumn{2}{|c|}{ Frekuensi } \\
\hline & & & \multirow{2}{*}{$\frac{\text { Relatif }}{3.75 \%}$} & \multirow{2}{*}{$\frac{\text { Komulatif (\%) }}{3.75 \%}$} \\
\hline 142 & $-\quad 145$ & & & \\
\hline 146 & $\begin{array}{ll}-\quad 149 \\
\end{array}$ & 1 & $1.25 \%$ & $5.00 \%$ \\
\hline 150 & $-\quad 153$ & 5 & $6.25 \%$ & $11.25 \%$ \\
\hline 154 & $\begin{array}{ll}-\quad 157 \\
\end{array}$ & 6 & $7.50 \%$ & $18.75 \%$ \\
\hline 158 & $\begin{array}{l}-\quad 161 \\
\end{array}$ & 10 & $12.50 \%$ & $31.25 \%$ \\
\hline 162 & $-\quad 165$ & 24 & $30.00 \%$ & $61.25 \%$ \\
\hline 166 & $\begin{array}{l}-\quad 169 \\
\end{array}$ & 21 & $26.25 \%$ & $87.50 \%$ \\
\hline 170 & $-\quad 173$ & 10 & $12.50 \%$ & $100.00 \%$ \\
\hline \multicolumn{2}{|c|}{ Jumlah } & 80 & $100 \%$ & \\
\hline
\end{tabular}




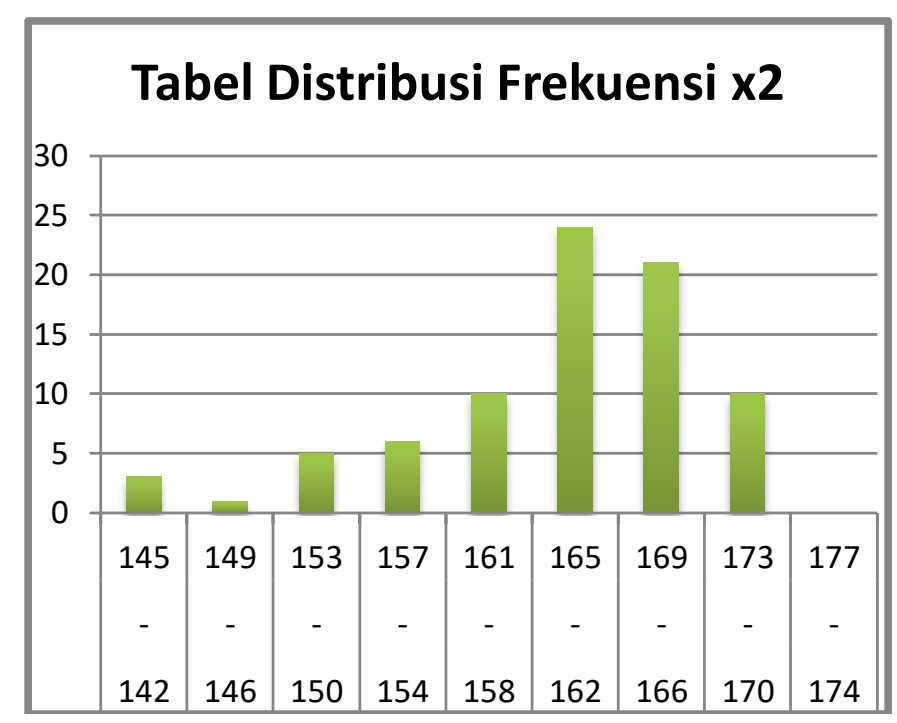

\section{Gambar Histogram Variabel Budaya Organisasi Sekolah $\left(\mathbf{X}_{2}\right)$}

Berdasarkan hasil uji persyaratan juga, pengujian hipotesis dapat dilakukan sebab sejumlah persyaratan yang ditentukan untuk pengujian hipotesis, seperti normalitas, validitas dan reliabilitas dari data yang diperoleh telah dapat dipenuhi. Pengujian hipotesis ini dilakukan dengan menggunakan teknik analisis yang meliputi analisis korelasi product moment dan analisis regresi baik secara sederhana maupun ganda dengan menggunakan program statistik SPSS.

Analisis korelasi product moment atau lengkapnya Product of the Moment Correlation adalah salah satu teknik untuk mencari korelasi antara dua variabel yang kerap kali digunakan. Disebut product moment correlation karena koefisien korelasinya diperoleh dengan cara mencari hasil perkalian dari moment-moment variabel yang dikorelasikan.

Pengaruh kompetensi manajerial kepala sekolah $\left(\mathrm{X}_{1}\right)$ dan budaya organisasi $\left(\mathrm{X}_{2}\right)$ secara simultan terhadap motivasi kerja guru (Y)

$$
\begin{array}{ccc}
\mathrm{H}_{0} \quad: \quad \tilde{\mathrm{n}}_{y_{1}}=0 \quad \begin{array}{l}
\text { Tidak terdapat pengaruh kompetensi manajerial } \\
\text { dan budaya organisasi sekolah terhadap } \\
\text { motivasi kerja guru. }
\end{array} \\
\mathrm{H}_{1} \quad: \quad \tilde{\mathrm{n}}_{y_{1}}>0 \begin{array}{l}
\text { Terdapat pengaruh kompetensi manajerial dan } \\
\text { budaya organisasi sekolah terhadap motivasi } \\
\text { kerja guru. }
\end{array}
\end{array}
$$

Tabel

Uji Determinasi Variabel $X_{1}$ terhadap $Y\left(\tilde{n}_{y_{2}}\right)$

\begin{tabular}{|c|l|l|l|l|}
\hline$R$ & $R$ & Adjusted $R$ & Std. Error of & Change Statistics \\
\hline
\end{tabular}




\begin{tabular}{|r|r|r|r|r|r|r|r|r|}
\hline & Square & Square & the Estimate & $\begin{array}{c}\text { R Square } \\
\text { Change }\end{array}$ & $\begin{array}{c}F \\
\text { Change }\end{array}$ & df1 & df2 & Sig. F Change \\
\hline $.500^{\mathrm{a}}$ &. $\mathbf{2 5 0}$ & .231 & 6.979 & .250 & 12.859 & 2 & 77 & .000 \\
\hline
\end{tabular}

Berdasarkan tabel di atas, dapat diketahui nilai koefisien korelasi melalui kolom R. Maka koefisien korelasi ganda kompetensi manajerial kepala sekolah dan budaya organisasi secara bersama-sama terhadap motivasi kerja guru sebesar 0,500.

Untuk mengetahui tingkat signifikansi koefisien korelasi ganda diuji secara keseluruhan berdasarkan tabel Model Summary di atas diperoleh nilai probabilitas (sig.F change $)=0,000$. Karena nilai sig.F change $0,000<0,05$, maka keputusannya adalah $\mathrm{H} 0$ ditolak dan Ha diterima. Artinya terdapat hubungan yang positif dan signifikan secara simultan antara kompetensi manajerial kepala sekolah $\left(\mathrm{X}_{1}\right)$ dan budaya organisasi sekolah $\left(\mathrm{X}_{2}\right)$ terhadap motivasi kerja guru $(\mathrm{Y})$.

Adapun besarnya pengaruh ditunjukkan oleh koefisien determinasi $\mathrm{R} 2(\mathrm{R}$ square $)=$ 0,250, yang berarti bahwa kompetensi manajerial kepala sekolah dan budaya organisasi secara simultan memberikan pengaruh terhadap motivasi kerja guru sebesar $25 \%$ dan sisanya yaitu $75 \%$ ditentukan oleh faktor lainnya.

\section{Tabel}

Uji Regresi Variabel $X_{1}$ dan $X_{2}$ terhadap Y $\left(\tilde{\mathrm{n}}_{y_{12}}\right)$

\begin{tabular}{|c|c|c|c|c|c|}
\hline \multirow[b]{2}{*}{ Model } & \multicolumn{2}{|c|}{$\begin{array}{c}\text { Unstandardized } \\
\text { Coefficients }\end{array}$} & \multirow{2}{*}{$\begin{array}{c}\text { Standardized } \\
\text { Coefficients } \\
\text { Beta }\end{array}$} & \multirow[b]{2}{*}{$\mathrm{t}$} & \multirow[b]{2}{*}{ Sig. } \\
\hline & B & Std. Error & & & \\
\hline 1 (Constant) & 44,471 & 22,346 & & 1,990 & ,050 \\
\hline $\begin{array}{l}\text { Kompetensi } \\
\text { Manajerial }\end{array}$ & .324 & ,105 & ,316 & 3,088 & ,003 \\
\hline $\begin{array}{l}\text { Budaya } \\
\text { organisasi } \\
\text { sekolah }\end{array}$ & ,370 & ,120 & ,315 & 3,978 & ,003 \\
\hline
\end{tabular}

a. Dependent Variable: Motivasi Kerja

Berdasarkan hasil analisis regresi ganda, ternyata persamaan regresi (unstandardized coefficients B) menunjukkan $\hat{\mathrm{Y}}=44,471+0,324 \mathrm{X}_{1}+0,370 \mathrm{X}_{2}$, yang berarti bahwa setiap 
Ainur Alam Budi Utomo

Vol 4 No 2

ISSN : 2541-6995

E ISSN : 2580-5517

peningkatan satu unit skor kompetensi manajerial kepala sekolah dan budaya organisasi sekolah secara simultan akan mempengaruhi peningkatan skor motivasi kerja guru sebesar 0,694 .

\section{PEMBAHASAN}

Untuk mengetahui hasil apakah korelasi ini positif atau negative diperlukan perhitungan koefisien regresi, dan didapatkan hasil pada konstanta sebesar 44,471 dan koefisien regresi Kompetensi Manajerial Kepala Sekolah sebesar 0,324 serta koefisien regresi Budaya Organisasi Sekolah sebesar 0,370. Maka dapat digambarkan bentuk pengaruh antara variabel Kompetensi Manajerial Kepala Sekolah dan Budaya Organisasi Sekolah secara bersama-sama terhadap Motivasi Kerja Guru dalam bentuk persamaan regresi $\hat{Y}=44,471+0,324 X_{1}+0,370 X_{2}$.

Sehingga dapat disimpulkan Jika variabel Kompetensi Manajerial Kepala Sekolah dan Budaya Organisasi Sekolah sebesar nol, maka variabel Motivasi Kerja Guru sebesar 44,471 unit skor. Jika variabel Kompetensi Manajerial Kepala Sekolah mengalami peningkatan sebesar satu poin sementara variabel Budaya Organisasi Sekolah dianggap tetap, maka variabel Motivasi Kerja Guru mengalami peningkatan sebesar 0,324 unit skor. Jika variabel Budaya Organisasi Sekolah mengalami peningkatan sebesar satu poin sementara variabel Kompetensi Manajerial Kepala Sekolah dianggap tetap, maka variabel Motivasi Kerja Guru mengalami peningkatan sebesar 0,370 unit skor. Sehingga antara vaiabel $\mathrm{X}_{1}$ dan $\mathrm{X}_{2}$ terhadap $\mathrm{Y}$ berpengaruh positive.

Berdasarkan hasil analisis varians di ketahui nilai $\mathrm{p}$ (sig.) $=0,000$ nilai lebih kecil dari $a=0.05$ at a u 5\% maka hipotesis nol diterima, hal ini berarti bahwa koefisien regresi $\mathrm{Y}$ atas X1 dan X2 di atas signifikan. Dengan demikian dapat disimpulkan bahwa persamaan regresi $\hat{Y}=44,471+0,324 X_{1}+0,370 X_{2}$ yang diperoleh adalah signifikan atau dengan kata lain terdapat pengaruh positif dan signifikan antara Kompetensi Manajerial Kepala Sekolah dan Budaya Organisasi Sekolah terhadap Motivasi Kerja Guru.

Berdasarkan perhitungan koefisien $\mathrm{r}$ diterminasi, $\mathrm{R}^{2}$ sebesar 0,250 atau $\mathrm{R}^{2}=25 \%$. Hal ini dapat ditarik kesimpulan bahwa variabel Kompetensi Manajerial Kepala Sekolah dan variabel Budaya Organisasi Sekolah memberikan pengaruh secara simultan sebesar 25 $\%$ terhadap Motivasi Kerja Guru dan sisanya sebanyak $75 \%$ dipengaruhi oleh faktor lain.

Kemudian nilai koefisien korelasi r product-moment telah diketahui sebesar 0,500. Telaah signifikansi terhadap nilai koefisien korelasi tersebut diperoleh nilai $r=0,500$, 
Ainur Alam Budi Utomo

Vol 4 No 2

ISSN : 2541-6995

E ISSN : 2580-5517

Karena nilai $\mathrm{r}>5 \%$ berarti hipotesis nol ditolak, hal ini menunjukkan adanya korelasi antara Kompetensi Manajerial Kepala Sekolah dan Budaya Organisasi Sekolah terhadap Motivasi Kerja Guru di Sekolah Islam Al-Hamîd Jakarta Timur. Karena nilai r product moment sebesar 0,500 maka artinya dapat diambil kesimpulan melalui tabel interpretasi korelasi Guilford bahwa pengaruh Kompetensi Manajerial Kepala Sekolah dan Budaya Organisasi Sekolah secara simultan terhadap Motivasi Kerja Guru berpengaruh sedang.

\section{KESIMPULAN DAN IMPLIKASI}

Berdasarkan hasil penelitian, maka dapat diambil kesimpulan terdapat pengaruh yang positif dan signifikan Kompetensi Manajerial Kepala Sekolah dan Budaya Organisasi Sekolah Secara simultan terhadap Motivasi Kerja Guru di Sekolah Islam Al-Hamîd Jakarta Timur dengan koefisien korelasi (r) sebesar 0,500 dan koefisien determinasi $\left(\mathrm{R}^{\mathrm{s}}\right)$ sebesar 25\%. Arah pengaruh ditunjukan dengan persamaan regresi $\hat{Y}=44,471+0,324 X_{1}+$ $0,370 \mathrm{X}_{2}$. Dari persamaan ini dapat dibaca bahwa setiap kenaikan 1 poin kompetensi manajerial kepala sekolah $\left(\mathrm{X}_{1}\right)$ dan Budaya Organisasi Sekolah $\left(\mathrm{X}_{2}\right)$ Secara bersama-sama akan diikuti kenaikan motivasi kerja guru (Y) sebesar 0,694 poin. Adapun implikasi yang didapat dari penelitian ini adalah sebagai berikut :

1. Hendaknya kepala sekolah menguasai kompetensi yang harus dimiliki, yaitu: edukator, manajer, administrator, supervisor, leader, innovator dan motivator. Dengan menguasai kompetensi tersebut secara teori dan praktik, kepala sekolah akan memberikan pengaruh yang positif terhadap kualitas pendidikan di sekolah itu sendiri menjadi sekolah sehat/efektif. Disamping itu juga, nilai plus dari Kompetensi Manajerial Kepala Sekolah akan mampu membangun budaya organisasi sekolah dan motivasi kerja guru di Sekolah Islam Al-Hamîd Jakarta Timur sehingga menjadi spirit ruhul jihad seperti yang diistilahkan oleh Baharuddin, yaitu dalam konteks manajemen spirit ruhul jihad tidak hanya dioperasionalkan dalam pendidikan dan pengajaran, tapi harus lebih spesifik seperti dalam penjaminan mutu dan pelayanan (diakses dari : http://pasca.uin-malang.ac.id/menciptakan-budaya-organisasi-yangunggul-di-lembaga-pendidikan islam/). Untuk itu, ada beberapa langkah untuk meningkatkan untuk Kompetensi Manajerial Kepala Sekolah, yaitu :

a. Kepala sekolah hendaknya senantiasa melatih gaya kepemimpinannya yang sesuai dengan harapan warga sekolah, sehingga akan terlihat kinerja sekolah itu sendiri. 
Ainur Alam Budi Utomo

Vol 4 No 2

ISSN : 2541-6995

E ISSN : 2580-5517

b. Visi dan Misi Kepala Sekolah hendakanya selalu tertanam kuat dalam dirinya dan disesuaikan dengan kebutuhan yang diterapkan dalam budaya organisasi sekolah.

c. Kepala sekolah hendaknya memelihara dan menjaga hubungan emosional dengan warga sekolah.

2. Budaya Organisasi Sekolah merupakan cerminan sekolah itu sendiri, oleh karenanya perlu adanya kesadaran kolektif dan kerja sama warga sekolah untuk mewujudkan budaya organisasi sekolah yang sehat sehingga akan terasa manfaatnya. Penelitian yang dilakukan di Sekolah Islam Al-Hamîd Jakarta Timur, budaya organisasi sekolah perlu ditingkatkan lagi dan dijadikan sebagai identitas sekolah.

3. Motivasi kerja guru merupakan faktor yang penting dalam menentukan keberhasilan sekolah. Tentunya motivasi kerja perlu dibina oleh kepala sekolah kepada warganya secara simultan. Kepala sekolah perlu memberdayakan SDM dan meningkatkan kebutuhan Guru itu sendiri. Adanya segala fasilitas yang ada di sekolah Islam AlHamîd Jakarta Timur, dan memiliki guru-guru yang berdedikasi dan berintegritas merupakan modal utama yang telah dimiliki oleh sekolah tersebut.

\section{DAFTAR PUSTAKA}

Anas Sudijono. (2000). Pengantar Statistik Pendidikan, Jakarta: Raja Grafindo Persada.

E. Mulyasa. (2013). Menjadi Kepala Sekolah Profesioanal, Bandung : PT Remaja Rosda Karya.

Nana Syaodih Sukmadinata. (2012). Metode Penelitian Pendidikan, Program Pascasarjana UPI dengan PT Remaja Rosdakarya.

Novianty Djafri. (2016). Manajemen Kepemimpinan Kepala Sekolah Pengetahuan Manajemen, efektivitas, kemandirian keunggulan bersaing, dan kecerdasan ekonomi, Yogyakarta : deepublish.

Ridwan. (2002). Skala Pengukuran Variabel-variabel Penelitian, Jakarta: Alfabetha.

Radar Karawang (2016, Januari 4). "Penerapan Pendidikan Karakter Bakal Ditingkatkan”. Sugiyono. (2006). Metode Penelitian Kuantitatif Kualitatif dan $R$ \& D, Bandung: Alfabetha.

Uhar Suharsaputra. (2013). Administrasi Pendidikan, Bandung : PT Refika Aditama.

2016. Diakses dari : https://www.cnnindonesia.com/nasional/20160906155806-20$\underline{\text { 156462/unesco-soroti-kesenjangan-kualitas-pendidikan-di-indonesia }}$ 
Ainur Alam Budi Utomo

Vol 4 No 2

ISSN : 2541-6995

E ISSN : 2580-5517

Baharuddin. 2016. Dikases dari : http://pasca.uin-malang.ac.id/menciptakan-budayaorganisasi-yang-unggul-di-lembaga-pendidikan-islam/

$\mathbf{2 8} \mid$ B u a n a I $1 \mathrm{~m}$ u 